\title{
New species of Hybos Meigen from Guangdong Province, South China (Diptera: Empididae)
}

\author{
DING YANG ${ }^{1,2}$, STEPHEN D. GAIMARI $^{3}$ and PATRICK GROOTAERT ${ }^{4}$ \\ ${ }^{1}$ Department of Entomology, China Agricultural University, Beijing 100094, China. \\ Email:dyangcau@yahoo.com.cn \\ ${ }^{2}$ Key Lab of Insect Evolution \& Environmental Changes, Capital Normal University, Beijing 100037, China \\ ${ }^{3}$ California State Collection of Arthropods, California Department of Food \& Agriculture, Plant Pest Diag- \\ nostics Branch, 3294 Meadowview Road, Sacramento, CA 95832-1448, USA, email: sgaimari@cdfa.ca.gov \\ ${ }^{4}$ Department of Entomology, Royal Belgian Institute of Natural Sciences, Vautierstraat 29, B-1000 Brussels, \\ Belgium. Email: Patrick.Grootaert@naturalsciences.be
}

\begin{abstract}
The following three new species of the genus Hybos Meigen, from Guangdong Province, China, are described as new to science: Hybos mangshanensis, H. nankunshanensis, H. xiaohuangshanensis. Their relationships with related species are discussed.
\end{abstract}

Key words: Diptera, Empididae, Hybotinae, Hybos, new species, Guangdong

\section{Introduction}

The cosmopolitan genus Hybos Meigen, 1803, belongs to the subfamily Hybotinae (Diptera: Empididae), and is characterized by the following features: proboscis long and spine-like, anal cell longer than basal cell, Rs rather short, and $\mathrm{R}_{4+5}$ and $\mathrm{M}_{1}$ divergent apically (Chvála 1983). When last catalogued, 37 species were known from the Oriental realm (Smith 1975) and nine from the Palaearctic realm (Chvála \& Kovalev 1989). Since then, for China alone, that number has increased to 85 described species (Yang \& Yang 2004).

The Guangdong Province has a subtropical to tropical climate, belonging to the southern region of China in the Oriental realm. Five species of Hybos were reported from this region recently by Liu et al. (2004). Herein, three new species are added for the fauna. The types of the new species are deposited in the Entomological Museum of China Agricultural University (CAU), Beijing. 
Basic terminology follows McAlpine (1981) and Cumming et al. (1995) for genitalia. The following abbreviations are used: $a c r$-acrostichal, $a d$-anterodorsal, $a v$-anteroventral, $d$-dorsal, $d c$-dorsocentral, $n p l$-notopleural, $o c$-ocellar, ppn-postpronotal, prscprescutellar, $p s a$-postalar, $p v$-posteroventral, $v$-ventral.

\section{TAXONOMY}

Hybos mangshanensis sp. nov.

(Figs. 1-4)

Diagnosis. Palpus with only 1 ventral hair at extreme tip. Legs entirely black. Wing grayish. Hypandrium with short thick subapical left lateral process bearing very long marginal bristles.

Adult, $o^{x}$ (ㅇ unknown). Body length $4.9 \mathrm{~mm}$, wing length $5.0 \mathrm{~mm}$.

Head. Black with pale gray pollen; hairs and bristles black. Eyes contiguous on frons, brown with enlarged upper facets yellow. Ocellar tubercle distinct, with 2 long oc and 2 very short hairs. Antenna black; scape without hairs; pedicel with circlet of subapical hairs; first flagellomere without dorsal hairs; arista black, short pubescent except apical 1/ 3 or so thin. Proboscis black; palpus black with 1 ventral hair at extreme tip.

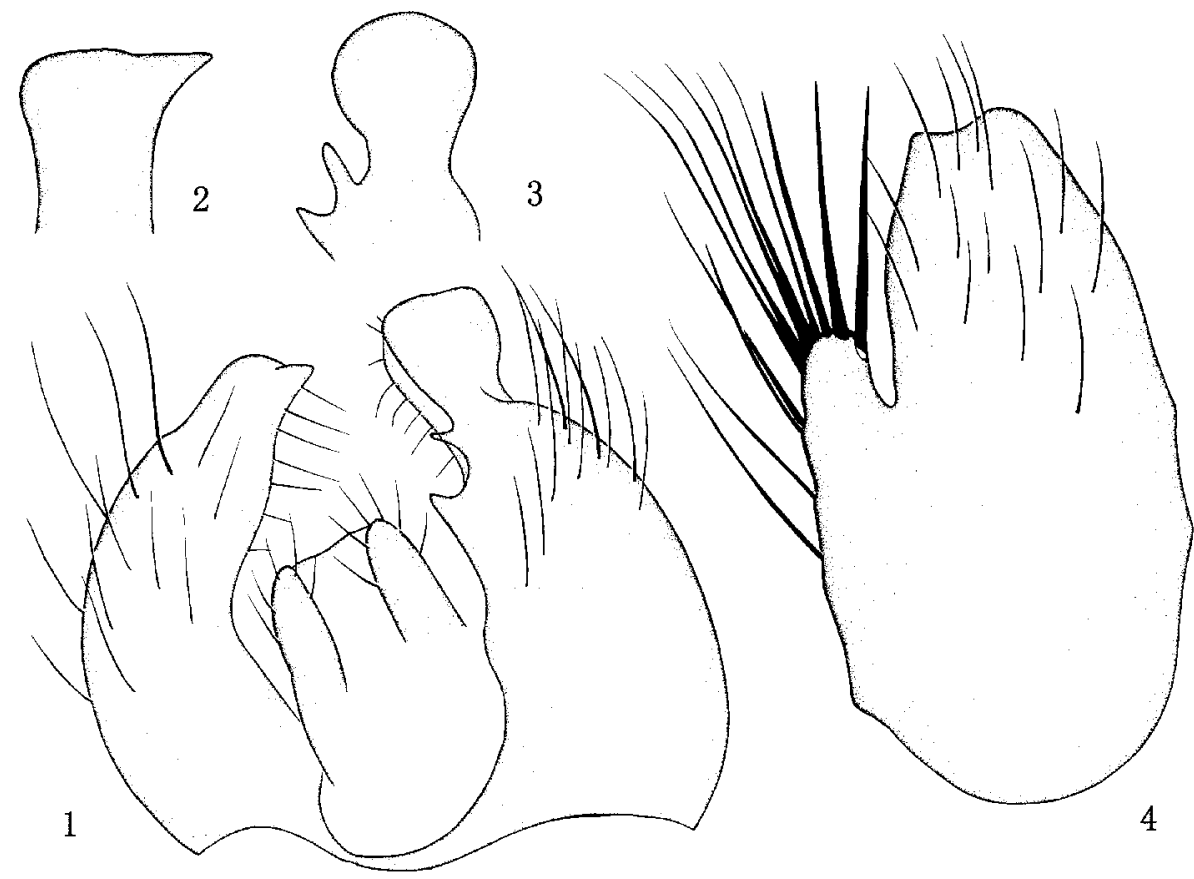

FIGURES 1-4. Hybos mangshanensis sp. nov., ơ. 1, Genitalia, dorsal view; 2, right surstylus; 3, left surstylus; 4, hypandrium, ventral view. 
Thorax. Black with pale gray pollen. Hairs and bristles black; ppn absent; $2 \mathrm{npl}$ (posterior one long); irregularly 4-seriate $a c r ; 1$ posterior $d c ; 1$ prsc; 1 psa; scutellum with some short marginal hairs and 2 long bristles. Legs entirely black; hairs and bristles black, except hind coxa with some brownish yellow posterior hairs and hind femur with brownish yellow dorsal hairs on basal 1/3. Fore femur 1.2 times wider than mid femur; hind femur 2.1 times wider than mid femur, with three rows of short spine-like $v$ on weak tubercles ( $8 a v$ longer, only $4 p v$ on basal 1/5); fore and mid femora each with row of very long hair-like $p v$. Fore tibia with $1 d$ at middle, long posterior hairs except basal $1 / 4$, apically with 3 bristles; mid tibia with $3 d$, apically with 4 bristles; hind tibia with row of 6 long hair-like $p d$ somewhat erect. Fore tarsomeres 1-2 each with long posterior hairs; hind tarsomeres 1-2 with row of short spine-like $v$. Wing grayish; veins dark brown; stigma long and dark brown. Squama brownish yellow with pale hairs. Halter brown with pale yellow knob.

Abdomen. Black with gray pollen; distinctly curved downward. Hairs and bristles pale, except those on hypandrium black.

Male genitalia (Figs. 1-4). Left epandrial lobe with slightly incised inner margin; left surstylus rounded apically, basally with two short acute processes. Right epandrial lobe with distinctly incised inner margin; right surstylus nearly truncate apically and with acute apicolateral corner. Hypandrium obtuse apically, with short thick subapical left lateral process bearing very long marginal bristles.

Type material. Holotype $\sigma^{\star}$, deposited in CAU: CHINA, Guangdong Province, Nanling National Nature Reserve, Mangshan, 1300 m, 2004. V. 8, Ding Yang.

Etymology. The specific epithet refers to the type locality, Mangshan.

Distribution. China (Guangdong Province).

Remarks. The new species is similar to Hybos dorsalis Yang et Yang, 1995, from Zhejiang Province, but may be separated from the latter by the palpus bearing only 1 ventral hair at the extreme tip and the wing is grayish. In H. dorsalis, the palpus has 3 ventral hairs, and the wing is hyaline (Yang \& Yang 2004).

\section{Hybos nankunshanensis sp. nov.}

(Figs. 5-8)

Diagnosis. Palpus with 1 ventral hair at extreme tip. Legs entirely black. Hypandrium rather wide apically with very long marginal bristles on slightly projected right apical corner.

Adult, ơ (o unknown). Body length 4.6-5.0 mm, wing length 4.3-4.7 mm.

Head. Black with pale gray pollen; hairs and bristles black. Eyes contiguous on frons, brownish yellow with enlarged upper facets yellow. Ocellar tubercle distinct, with 2 long $o c$ and 2 very short hairs. Antenna black; scape without hairs; pedicel with circlet of sub- 


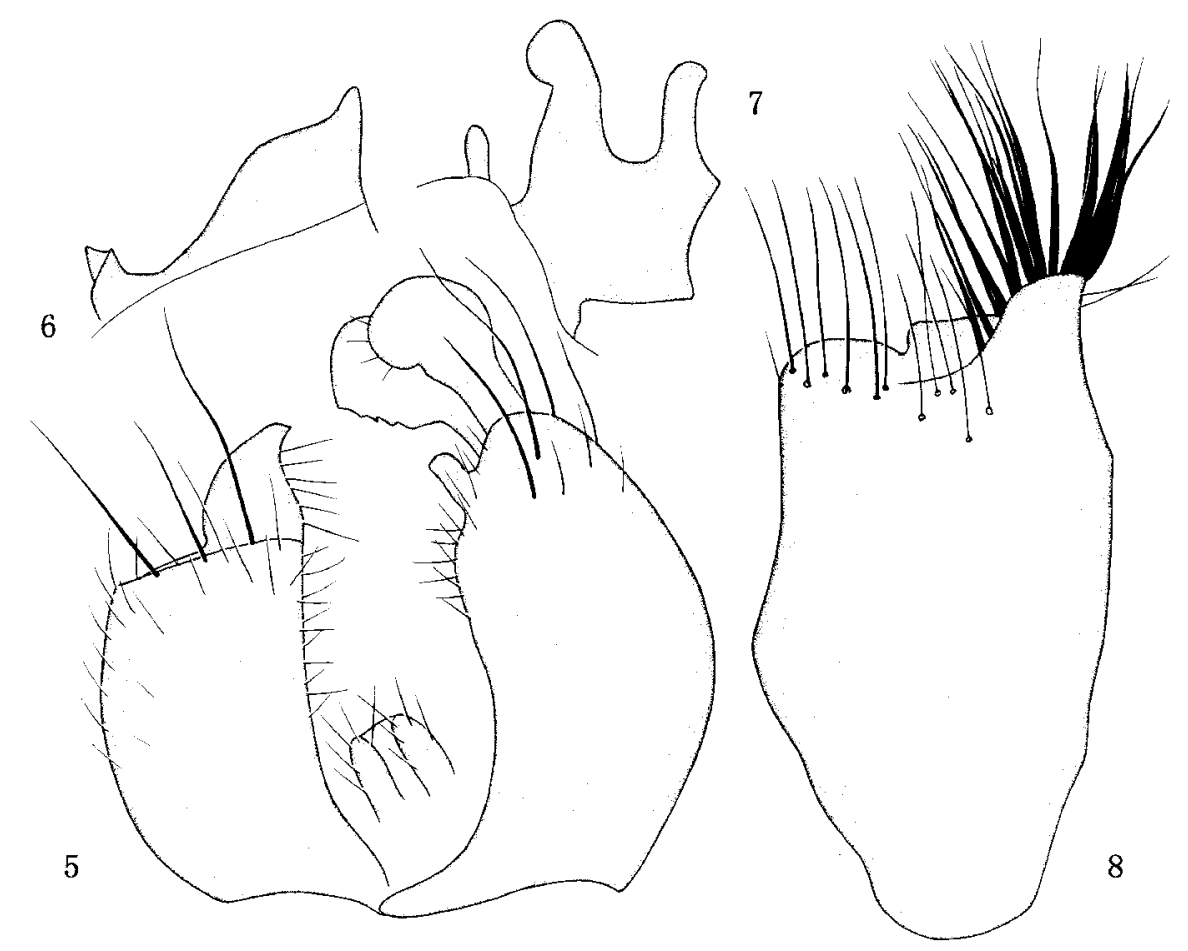

FIGURES 5-8. Hybos nankunshanensis sp. nov., ơ. 5, Genitalia, dorsal view; 6, right surstylus; 7, left surstylus; 8, hypandrium, ventral view.

Thorax. Black with pale gray pollen. Hairs and bristles black; $p p n$ absent; $2 \mathrm{npl}$ (posterior one long); irregularly 4-seriate $a c r ; 1$ posterior $d c ; 1 \mathrm{prsc} ; 1 \mathrm{psa}$; scutellum with some short marginal hairs and 2 long bristles. Legs entirely black; hairs and bristles black. Fore femur 1.3 times wider than mid femur; hind femur 2.0 times wider mid femur, with $4 \mathrm{ad}$, and with three rows of short spine-like $v$ on weak tubercles ( $9 a v, 4$ basal $a v$ short but other $5 a v$ long); fore and mid femora each with row of long hair-like $p v$. Fore tibia with $1 d$ at middle, very long posterior hairs except basal 1/4, apically with 2 bristles; mid tibia with 2 $d$ on basal half, apically with 4 bristles. Fore tarsomeres $1-2$ each with row of very long posterior hairs and with pair of preapical very long hair-like $d$; mid tarsomere 1 with 1 very long preapical $d$; hind tarsomeres 1-2 with two rows of short spine-like $v$. Wing hyaline; veins dark brown; stigma long and dark brown. Squama yellow with pale hairs. Halter brownish with yellow knob.

Abdomen. Black with gray pollen; distinctly curved downward. Hairs and bristles pale and black, except those on hypandrium only black. 
Male genitalia (Figs. 5-8). Left epandrial lobe long with slightly incised inner margin; left surstylus large and nearly quadrate with deep apical incision, and basally with a short finger-like lateral process. Right epandrial lobe shorter than left epandrial lobe with weak inner notch; right surstylus short and wide with oblique apical incision. Hypandrium with small apical incision, with very long marginal bristles on slightly projected right apical corner.

Type material. Holotype $\sigma^{\star}$, deposited in CAU: CHINA, Guangdong Province, Nankunshan National Nature Reserve, 2004. V. 12, Ding Yang. Paratype, $1{ }^{\star}$, same data as holotype.

Etymology. The specific epithet refers to the type locality, Nankunshan.

Distribution. China (Guangdong Province).

Remarks. The new species is somewhat similar to Hybos marginatus Yang et Yang, 1989, from Sichuan Province, but may be separated from the latter by the mid tibia bearing only $2 d$. In H. marginatus, the mid tibia bears $3 d$ and $1 v$ (Yang \& Yang 2004).

\section{Hybos xiaohuangshanensis sp. nov.}

(Figs. 9-12)

Diagnosis. Arista bare. Legs black except hind knee (distal femur and proximal tibia) and mid and hind tarsi brownish yellow. Hypandrium obliquely incised apically, with long marginal bristles.

Adult, ơ (\% unknown). Body length 7.7-7.9 mm, wing length 7.3-7.4 mm.

Head. Black with pale gray pollen; hairs and bristles on head black. Eyes contiguous on frons, pale reddish brown with enlarged upper facets reddish yellow. Ocellar tubercle distinct, with 2 long $o c$ and 2 very short hairs. Antenna black; scape without hairs; pedicel with circlet of subapical hairs; first flagellomere without dorsal hairs; arista black, bare, with apical $1 / 5$ or so thin. Proboscis black; palpus black with 5 ventral hairs.

Thorax. Black with pale gray pollen; mesonotum anteriorly with large subshiny black lateral area. Hairs and bristles black; ppn absent; $2 \mathrm{npl}$ (posterior $\mathrm{npl}$ long); irregularly 4seriate $a c r ; 1$ posterior $d c$; prsc absent; 1 psa; scutellum with some short marginal hairs and 2 long bristles. Legs black except hind knee yellow and mid and hind tarsi brownish yellow; hairs and bristles black. Fore femur 1.2 times wider than mid femur; hind femur 2.4 times wider than mid femur, with $5 \mathrm{ad}$, and with three rows of short spine-like $v$ on weak tubercles (13av long, only $4 p v$ on basal 1/4); fore and mid femora each with row of very long hair-like $p v$. Fore tibia with 4-5 $a d$, very long posterior hairs (except basal 1/4), apically with 5 bristles; mid tibia with 2 long $d$ on basal half and $2 a d$ on apical half, apically with 4 bristles. Fore tarsomeres 1-2 with row of very long lateral hairs on each side; hind tarsomeres 1-2 with row of short spine-like $v$. Wing hyaline; veins dark brown; stigma long and brown. Squama brownish yellow with pale hairs. Halter brown with yellow knob. 
Abdomen. Black with gray pollen; distinctly curved downward. Hairs and bristles on abdomen mostly pale, except those of hypandrium black.

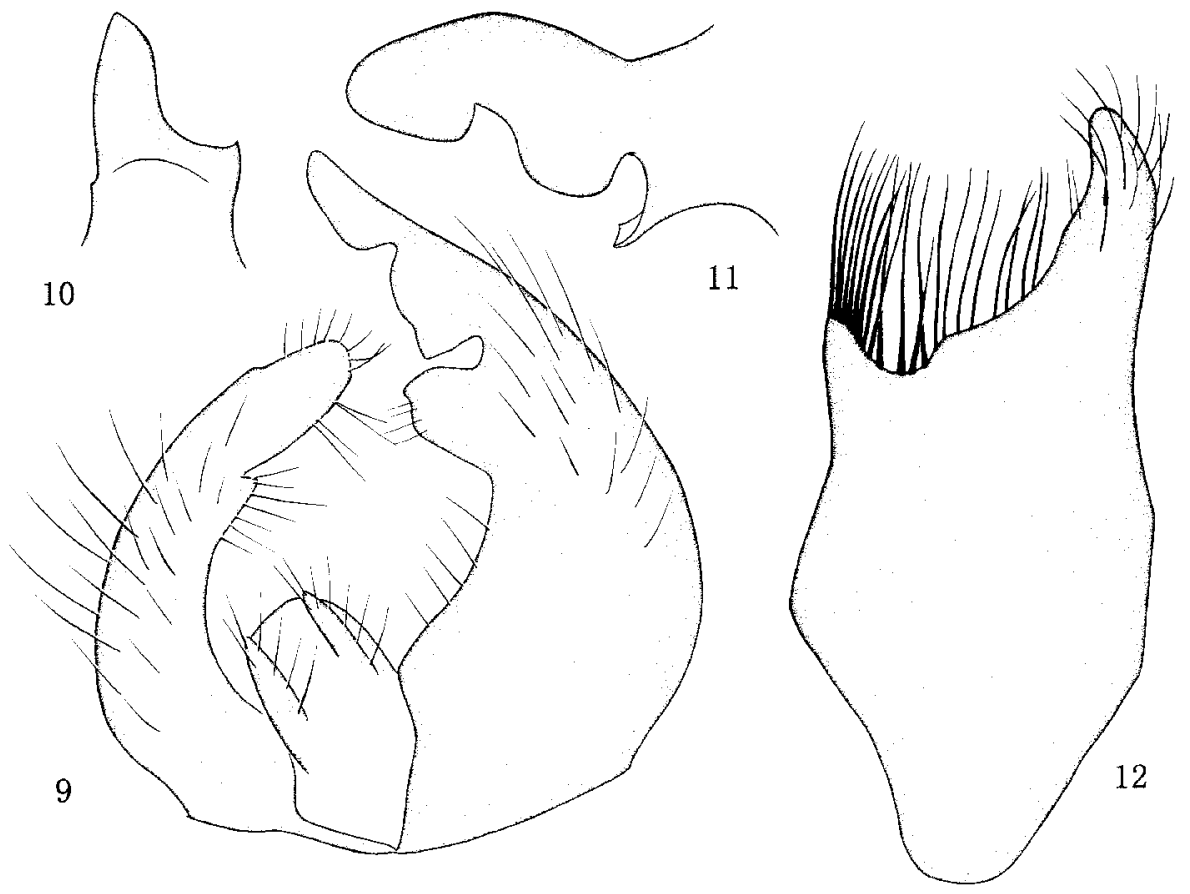

FIGURES 9-12. Hybos xiaohuangshanensis sp. nov., ơ. 9, Genitalia, dorsal view; 10, right surstylus; 11, left surstylus; 12, hypandrium, ventral view.

Male genitalia (Figs. 9-12). Left epandrial lobe long with convex inner margin near base; left surstylus long, obtuse apically and with irregular lateral incisions. Right epandrial lobe shorter than left epandrial lobe with weak inner notch; right surstylus short, wide basally and with acute tip. Hypandrium obliquely incised apically, with long marginal bristles.

Type material. Holotype $0^{x}$, deposited in CAU: CHINA, Guangdong Province, Ruyuan, Nanling National Nature Reserve, Xiaohuangshan, 1500 m, 2004. V. 9, Ding Yang. Paratype $1 \mathrm{o}^{x}$, same data as holotype.

Etymology. The specific epithet refers to the type locality, Xiaohuangshan.

Distribution. China (Guangdong Province).

Remarks. The new species is somewhat similar to Hybos hunanensis Yang et Yang, 1988, from Hunan Province, but may be separated from the latter by the arista being bare and the legs with the hind knee and mid and hind tarsi being brownish yellow. In $H$. hunanensis, the arista is minutely pubescent, and the legs are entirely black (Yang \& Yang 2004). 
We are indebted to Prof. Zaifu Xu (South China Agricultural University, Guangzhou) for his kind help in many ways during the survey to Guangdong, and Mrs. Mengqing Wang (China Agricultural University, Beijing) for her help during the study. The research was funded by the National Natural Science Foundation of China (No. 30070100, No. 30225009) and the California Department of Food and Agriculture.

\section{References}

Chvála, M. (1983) The Empidoidea (Diptera) of Fennoscandia and Denmark. II. General Part. The families Hybotidae, Atelestidae and Microphoridae. Fauna Entomologica Scandinavica, 12, $1-279$.

Chvála, M. \& Kovalev, V.G. (1989) Family Hybotidae. In: Soós, Á. \& L. Papp (eds.), Catalogue of Palaearctic Diptera, Volume 6, Elsevier Science Publishers and Akadémiai Kiadó, Amsterdam and Budapest, pp. 174-227.

Cumming, J.M., Sinclair, B.J. \& Wood, D.M (1995) Homology and phylogenetic implications of male genitalia in Diptera-Eremoneura. Entomologica Scandinavica, 26, 121-151.

Liu, X., Yang, D. \& Grootaert, P. (2004) A review of the species of Hybos Meigen, 1803 from Guangdong (Diptera: Empidoidea; Hybotinae). Annales Zoologici, 54(3), 525-528.

McAlpine, J.F. (1981) Morphology and TerminologyAdults. In: McAlpine, J.F., Peterson, B.V., Shewell, G.E., Teskey, H.J., Vockeroth, J.R., \& Wood, D.M. (coords.), Manual of Nearctic Diptera, Volume 1, Research Branch, Agriculture Canada, Ottawa, Monograph 27, pp 9-63.

Meigen, J.W. (1803) Versuch einer neuen Gattungseintheilung der europäischen zweiflügeligen Insekten. Magazin für Insektenkunde, 2, 259-281.

Smith, K.G.V. (1975) Family Empididae. In: Delfinado, M.D. \& Hardy, D.E. (Eds.), A Catalog of the Diptera of the Oriental Region, Volume 2, The University Press of Hawaii, Honolulu, pp 185-211.

Yang, C. \& Yang, D. (1989) Four new species of the genus Hybos from Sichuan (Diptera: Empididae). Journal of Southwest Agricultural University, 11(2), 155-158.

Yang, D. \& Yang, C. (1988) New species of Hybos Meigen from China (Diptera: Empididae). Acta Agriculturae Universitatis Pekinensis, 14(3), 282-287.

Yang, D. \& Yang, C. (1995) Diptera: Empididae. In: Wu, H. (Ed.), Insects of Baishanzu Mountain, Eastern China, China Forestry Publishing House, Beijing, pp 499-509.

Yang, D. \& Yang, C. (2004) Diptera, Empididae, Hemerodromiinae, Hybotinae. Fauna Sinica Insecta, 34, 1-329. 